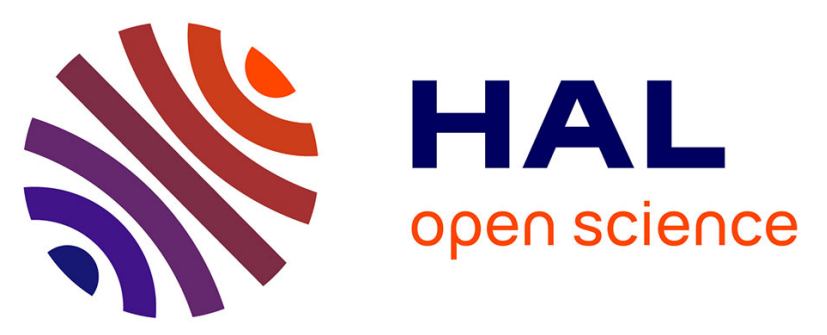

\title{
A phase I/II study of oxaliplatin and paclitaxel in patients with non-resectable cancer of the oesophagus and adenocarcinoma of the gastro-oesophageal junction: a study of the Arbeitsgemeinschaft Internistische Onkologie
}

Volker Kaechele, Markus Moehler, Manfred P. Lutz, Goetz Wichert, Miriam Eisele, Jochen Klaus, Peter R. Galle, Guido Adler, Thomas Seufferlein

\section{- To cite this version:}

Volker Kaechele, Markus Moehler, Manfred P. Lutz, Goetz Wichert, Miriam Eisele, et al.. A phase I/II study of oxaliplatin and paclitaxel in patients with non-resectable cancer of the oesophagus and adenocarcinoma of the gastro-oesophageal junction: a study of the Arbeitsgemeinschaft Internistische Onkologie. Cancer Chemotherapy and Pharmacology, 2010, 66 (1), pp.191-195. 10.1007/s00280-0101312-2 . hal-00581542

\author{
HAL Id: hal-00581542 \\ https://hal.science/hal-00581542
}

Submitted on 31 Mar 2011

HAL is a multi-disciplinary open access archive for the deposit and dissemination of scientific research documents, whether they are published or not. The documents may come from teaching and research institutions in France or abroad, or from public or private research centers.
L'archive ouverte pluridisciplinaire HAL, est destinée au dépôt et à la diffusion de documents scientifiques de niveau recherche, publiés ou non, émanant des établissements d'enseignement et de recherche français ou étrangers, des laboratoires publics ou privés. 


\title{
A phase I/II study of oxaliplatin and paclitaxel in patients with non-resectable cancer of the oesophagus and adenocarcinoma of the gastro-oesophageal junction: a study of the Arbeitsgemeinschaft Internistische Onkologie
}

\author{
Volker Kaechele $\cdot$ Markus Moehler $\cdot$ Manfred P. Lutz \\ Goetz von Wichert • Miriam Eisele · Jochen Klaus • \\ Peter R. Galle · Guido Adler · Thomas Seufferlein \\ Received: 10 January 2010 / Accepted: 12 March 2010 / Published online: 31 March 2010 \\ (C) Springer-Verlag 2010
}

\begin{abstract}
Purpose To assess the efficacy and toxicity of paclitaxel and oxaliplatin in patients with non-resectable cancer of the oesophagus and adenocarcinoma of the gastro-oesophageal junction.

Methods Treatment consisted of oxaliplatin $85 \mathrm{mg} / \mathrm{m}^{2}$ and paclitaxel $90 \mathrm{mg} / \mathrm{m}^{2}$ on days 1,15 and 29 every 6 weeks. Patients with a non-resectable cancer of the oesophagus and/or adenocarcinoma of the gastro-oesophageal junction were eligible.

Results Twenty-six chemotherapy-naive patients were enrolled who had the following characteristics: median age 59.5 years (range 46-81); ECOG scores of $0 / 1 / 2$ for $7 / 16 / 3$ patients, respectively, and $23(88 \%)$ patients had metastatic disease. There were 5 patients $(19 \%)$ with adenocarcinoma of the gastro-oesophageal junction and 21 patients $(81 \%)$ with oesophageal cancer; 19 (73\%) had a squamous cell cancer and
\end{abstract}

V. Kaechele · G. von Wichert · M. Eisele · J. Klaus ·

G. Adler · T. Seufferlein

Klinik für Innere Medizin I, Universitätsklinikum Ulm,

Albert-Einstein-Allee 23, 89081 Ulm, Germany

M. Moehler · P. R. Galle

Abteilung Innere I,

Universitätsklinikum Johannes Gutenberg-Universität Mainz,

Langenbeckstr. 1, 55131 Mainz, Germany

M. P. Lutz

Caritasklinik St. Theresia, Rheinstraße 2,

66113 Saarbrücken, Germany

T. Seufferlein $(\square)$

Klinik für Innere Medizin I, Universitätsklinikum

Martin-Luther-Universität Halle-Wittenberg,

Ernst-Grube-Strasse 40, 06120 Halle, Germany

e-mail: thomas.seufferlein@medizin.uni-halle.de
$7(27 \%)$ had an adenocarcinoma. NCI grade 4 toxicity (neutropenia) was observed in one patient. Non-haematological toxicity consisted mainly of grade $1 / 2$ neurosensory toxicity. The overall response rate by the intention-to-treat analysis was $15 \%$ with 4 patients having confirmed partial response. Overall tumour control rate was $73 \%$. Median overall survival was 12.3 months (range 1.5-66) and median time to progression was 4.5 months (range 0.8-19.3).

Conclusion This regimen is well tolerated and demonstrates a modest response rate with a favourable disease control rate.

Keywords Oxaliplatin · Paclitaxel ·

Cancer of the gastro-oesophageal junction .

Oesophageal cancer · Chemotherapy

\section{Introduction}

Carcinoma of the upper gastrointestinal tract represents a major health problem worldwide [1, 2]. About $90 \%$ of all patients diagnosed with oesophageal cancer will die as a consequence of this disease. Besides the predominantly late diagnosis, another reason for this poor prognosis of this tumour is the limited effectiveness of systemic therapy.

Even if there is no established standard chemotherapy regimen, cisplatin-containing combination therapies are accepted as a standard of care. Oxaliplatin is a third-generation platinum compound with a favourable toxicity profile as compared to cisplatin [3, 4].

Taxanes, microtubule-stabilising agents initially isolated from the Pacific yew, have been extensively studied in gastro-oesophageal cancer. Paclitaxel and Docetaxel demonstrated encouraging activity in single and combination therapy [5-8]. 
Oxaliplatin is a potent inhibitor of Survivin, which enhances paclitaxel-induced apoptosis and mitotic catastrophe in colon and gastric cancer cell lines. These findings made the combination of these two drugs an attractive option for clinical trials $[9,10]$.

This phase I/II study was conducted to assess the efficacy and tolerability of paclitaxel and oxaliplatin in patients with non-resectable cancer of the oesophagus and/ or adenocarcinoma of the gastro-oesophageal junction. The treatment regimen was adapted from a phase II study by Petrasch in which paclitaxel $90 \mathrm{mg} / \mathrm{m}^{2}$ was followed by cisplatin $50 \mathrm{mg} / \mathrm{m}^{2}$ resulting in an overall remission rate of $40 \%$ (8/20) including 15\% (3/20) clinically complete responses with a favourable toxicity profile [11]. By substituting oxaliplatin for cisplatin we aimed at obtaining an even better tolerability.

\section{Methods}

Patients

Patients with non-resectable cancer of the oesophagus and adenocarcinoma of the gastro-oesophageal junction were eligible for this study. A measurable lesion according to the RECIST criteria was required [12]. Prior surgery and/or radiochemotherapy was allowed as well as one prior chemotherapy in a neoadjuvant or adjuvant setting that did not contain oxaliplatin and/or taxanes. This chemotherapy had to be terminated at least 6 months prior to enrolment into the study. This paper focusses on the subgroup of 26 chemotherapy-naive patients ( $84 \%$ of the whole study population). The remaining five patients had previously received systemic chemotherapy. An ECOG performance status of $\leq 2$ was mandatory as well as adequate bone marrow, kidney and liver function.

Chemotherapy schedules and treatment evaluation

Oxaliplatin $85 \mathrm{mg} / \mathrm{m}^{2}$ was administered over $2 \mathrm{~h}$ followed by paclitaxel $90 \mathrm{mg} / \mathrm{m}^{2}$ over $3 \mathrm{~h}$ both on day 1 . Treatment was administered fortnightly.

All patients were assessed for toxicity during the study period according to the National Cancer Institute Common Toxicity Criteria (NCI-CTC). Oxaliplatin-related peripheral neuropathy was described on a scale from 1 to 4 adapted from the classification of Wasserman et al. [13].

According to the study protocol an evaluation of tumour response was mandatory every 6 weeks. For locally advanced cancer a further evaluation regarding secondary resectability was obligatory after 12 weeks. Response and overall survival were assessed using an intent-to-treat analysis.

\section{Statistical considerations}

The response rate was the primary end point of this phase I/II trial. Chemotherapy-naive and pre-treated patients were analysed separately. A Chi-square test was utilised.

For chemotherapy-naive patients a sample size of 38 patients, who were assessable for response evaluation, was calculated to reject an initial hypothesis (H0) of a response rate $\leq 30 \%$ with an alpha error of 0.1 .

For the calculation of the sample size the programme, nQuery Advisor Release 3.0 (Statistical Solutions Ltd., Cork, Ireland, 1999), was used.

An interim analysis after inclusion of 25 chemo-naive patients revealed that the response rates were too low to reject the H0 hypothesis. Subsequently, recruitment was stopped prematurely.

\section{Results}

Between November 2002 and May 200531 patients were enrolled into the study at the two participating centres (University hospitals of Ulm and Mainz in Germany). A total of 64 cycles was administered to 26 chemotherapynaive patients. The patient demographic data and characteristics are summarised in Table 1. Patients with CNS metastasis, uncontrolled heart disease and/or clinical evidence of pre-existing peripheral neuropathy were excluded.

\section{Toxicity}

Of the 26 chemo-naive patients, 23 (88\%) were evaluable for toxicity; 3 patients could not be evaluated owing to early withdrawal of consent or early dropout for reasons other than toxicity prior to, or during, the first cycle of treatment. The majority of toxic effects were grade $1 / 2$, whereas grade $3 / 4$ toxicity was rare. Events leading to hospitalisation occurred in five patients; one patient had two hospitalisations. Three patients required endoscopic intervention because of an increase in dysphagia $(n=3)$. Other causes were ileus owing to peritoneal carcinosis $(n=1)$, hypercalcemia $(n=1)$ and pneumonia $(n=1)$.

\section{Haematological toxicity}

Haematological toxicity was rare. Overall $13 \%$ of patients $(n=3)$ experienced grade $3 / 4$ neutropenia. Febrile neutropenia was not observed. One patient had grade 3 thrombopenia. 
Table 1 Characteristics of chemo-naive patients $(n=26)$

\begin{tabular}{lll}
\hline Characteristic & Number of patients & $\%$ \\
\hline Sex & & \\
Male & 23 & 88 \\
Female & 3 & 12 \\
Age (years) & & \\
Median & 59.5 & \\
Range & $46-81$ & \\
ECOG performance status & & 27 \\
0 & 7 & 61 \\
1 & 16 & 12 \\
2 & 3 & 88 \\
Tumour stage (UICC) & & \\
III & 3 & 81 \\
IV & 23 & 46 \\
Tumour localisation & & 35 \\
Oesophagus & 21 & 19 \\
Mid-part & 12 & \\
Lower part & 9 & \\
Gastro-oesophageal junction & 5 & \\
Tumour histology & 19 & \\
Squamous cell carcinoma & 7 & \\
Adenocarcinoma & & \\
\hline
\end{tabular}

Non-haematological toxicity

No grade 4 non-haematological toxicity was encountered; $87 \%(n=20)$ encountered neurosensory toxicity $\geq$ grade 1 , but only $13 \%(n=3)$ had grade 3 neurosensory toxicity leading to a dose reduction of oxaliplatin. One patient had a hypersensitivity grade 2 shortly after infusion of paclitaxel during the third treatment cycle. There was only grade $1 / 2$ gastrointestinal toxicity that included diarrhoea grade 1 in $17 \%$, nausea in $22 \%$, emesis in $9 \%$ and mucositis in $9 \%$ of the patients. These findings are summarised in Table 2.

Treatment efficacy

\section{Response}

The overall confirmed response rate for all treatment-naive patients $(n=26)$ by the intention-to-treat analysis was $15 \%$ with four patients having a confirmed partial response. Together with 15 patients who achieved stable disease during the initial restaging the disease control rate was $73 \%$. This included two patients enrolled who did not undergo radiological response evaluation, because they exited the study early for reasons other than tumour progression: one patient exited the study during the first treatment cycle owing to early withdrawal of consent; one patient was excluded owing to surgery of symptomatic bone metastasis that was already prevalent at the time of entering the trial.

\section{Time to progression}

Twenty-four patients were included for the calculation of TTP. Two patients who changed to another treatment regimen (definitive radio-chemotherapy) without progress during the investigational treatment were excluded from
Table 2 Toxicity and efficacy of the treatment

\begin{tabular}{|c|c|c|c|}
\hline Toxicity NCI grade $2 / 3 / 4(n=23)$ & Grade $2(\%)$ & Grade $3(\%)$ & Grade $4(\%)$ \\
\hline Neutropenia & $4(n=1)$ & $9(n=2)$ & $4(n=1)$ \\
\hline Thrombopenia & - & $4(n=1)$ & - \\
\hline Neurosensory toxicity & $9(n=2)$ & $13(n=3)$ & - \\
\hline Nausea & $22(n=5)$ & - & - \\
\hline Emesis & $9(n=2)$ & - & - \\
\hline Infection (broncho-pulmonary or PEG-infection) & $22(n=5)$ & $4(n=1)$ & - \\
\hline Allergic reaction (due to paclitaxel) & $4(n=1)$ & - & - \\
\hline Cutaneous toxicity (aggravation of neurodermitis) & - & $4(n=1)$ & - \\
\hline Mucositis & $9(n=2)$ & - & - \\
\hline Hand-foot syndrome & $4(n=1)$ & - & - \\
\hline \multicolumn{4}{|l|}{ Efficacy intent-to-treat analysis $(n=26)$} \\
\hline Confirmed PR & \multicolumn{3}{|c|}{$4(15 \%)($ per protocol analysis $17 \%, n=24)$} \\
\hline Stable disease (SD) & \multicolumn{3}{|c|}{$15(58 \%)$} \\
\hline $\mathrm{PR}+\mathrm{SD}$ & \multicolumn{3}{|c|}{$19(73 \%)($ confirmed $\mathrm{PR}+\mathrm{SD} 58 \%, n=15)$} \\
\hline PD & \multicolumn{2}{|c|}{$7(27 \%)$} & \\
\hline Median TTP $(n=24)$ & \multicolumn{2}{|c|}{4.5 months } & \\
\hline Median OS & \multicolumn{2}{|c|}{12.3 months } & \\
\hline
\end{tabular}


the TTP analysis. The median TTP was 4.5 months (range 0.8-19.3) with a 1-year progression-free survival rate of $13 \%$.

\section{Overall survival}

The median OS for chemotherapy-naive patients was 12.3 months (range 1.5-66) with 1-year survival rate of $50 \%$. Table 2 provides an overview.

Information on the second-line treatment was available for 24 patients $(92 \%)$; 10 patients $(42 \%)$ did not receive further systemic treatment after discontinuation of the study, whilst 4 patients had radio-chemotherapy and 10 patients had chemotherapy alone.

\section{Discussion}

This study was conducted to assess the efficacy and tolerability of paclitaxel and oxaliplatin in patients with nonresectable cancer of the oesophagus and/or adenocarcinoma of the gastro-oesophageal junction. The primary goal of the study to reject the initial hypothesis ( $\mathrm{H} 0)$ of a response rate $\leq 30 \%$ was not met.

Oxaliplatin was given at a dose of $85 \mathrm{mg} / \mathrm{m}^{2}$ fortnightly which is commonly used within the FOLFOX4-regimen in colorectal cancer or the FLO-regimen in gastric cancer $[4,14]$. The oxaliplatin dose administered compared well to other oxaliplatin/taxane-containing doublets for the treatment of oesophago-gastric cancer. A phase II trial by Richards used $130 \mathrm{mg} / \mathrm{m}^{2}$ oxaliplatin together with Docetaxel $60 \mathrm{mg} / \mathrm{m}^{2}$ on day 1 of a 3 -week treatment cycle in patients with advanced gastric cancer and/or adenocarcinoma of the gastro-oesophageal junction [15]; $36 \%$ had a partial response and $40 \%$ of the patients in this trial had at least stable disease 6 months after entry into the study. Median PFS and OS were 4.3 and 8.5 months, respectively; $70 \%$ had grade $3 / 4$ neutropenia.

In oesophageal cancer the use of paclitaxel was investigated in different platinum-containing doublets: in a phase I study in metastatic oesophageal cancer paclitaxel was administered weekly as a 1-h infusion at a dose of $100 \mathrm{mg} /$ $\mathrm{m}^{2}$ followed by a 1-h infusion of carboplatin targeting an AUC of $2-5 \mathrm{mg} \times \mathrm{min} / \mathrm{ml}$. Of 37 patients evaluable for response, 1 complete response and 19 partial responses accounted for an overall response rate of 54\% [16]. In a phase II study for patients with resectable squamous cell carcinoma of the oesophagus, paclitaxel $180 \mathrm{mg} / \mathrm{m}^{2}$ and cisplatin $60 \mathrm{mg} / \mathrm{m}^{2}$ were given fortnightly with a similar response rate of 59\%; a grade $3 / 4$ neutropenia occurred in $71 \%$ of patients. With a median OS of 9 months for all patients this excellent response rate did not lead to an improved OS [17]. One reason for the inferior response rate in our trial was that we examined a lower dose of paclitaxel (90 mg/m $\mathrm{m}^{2}$ every 2 weeks as compared to $175 \mathrm{mg} / \mathrm{m}^{2}$ every 3 weeks or $135 \mathrm{mg} / \mathrm{m}^{2}$ every 2 weeks), although we used an equivalent dose of oxaliplatin.

The drug combination of paclitaxel and oxaliplatin was used in first-line treatment of patients with advanced NSCLC and ovarian cancer (paclitaxel $175 \mathrm{mg} / \mathrm{m}^{2}$ and oxaliplatin $130 \mathrm{mg} / \mathrm{m}^{2}$ given every 21 days), in both tumours with impressive response rates $[18,19]$. In advanced gastric cancer, a phase II trial added leucovorin $400 \mathrm{mg} / \mathrm{m}^{2}$ and 5 -FU $2,400 \mathrm{mg} / \mathrm{m}^{2}$ to paclitaxel $135 \mathrm{mg} / \mathrm{m}^{2}$ and oxaliplatin $85 \mathrm{mg} / \mathrm{m}^{2}$ given fortnightly; 12 out of 21 patients with measurable lesions had a treatment response. In $30 \%$ of the patients, neutropenia grade $3 / 4$ occurred [20].

Our study protocol differs from other recently published trials that yielded response rates higher than $40 \%[3,4,7,8]$ owing to the lack of a fluoropyrimidine compound, which might be a reason for the lower response rate observed here. We used a sequence of oxaliplatin followed by paclitaxel as compared to the reverse sequence applied in the other trials $[18,19]$. Pre-clinical data published shortly after the end of our recruitment period revealed that in human cancer cell lines the sequence of paclitaxel followed by oxaliplatin showed synergistic effects on apoptosis, whereas the opposite sequence potentially yielded antagonistic effects [21]. In contrast, a recently published phase I study provided a favourable pharmacokinetic profile for the sequence used in our study regimen [22].

\section{Conclusions}

Taken together, in a palliative setting when response rate is not paramount, our treatment protocol achieved a satisfactory disease control rate. The mTTP of 4.5 months observed in this trial and the mOS of 12.3 months are also comparable to other but often more toxic regimens. However, a second-line treatment which was administered in $58 \%$ of patients might have influenced this parameter. However, the response rate observed does not qualify our treatment regimen for a neoadjuvant setting. Thus, our results suggest that this regimen with oxaliplatin and paclitaxel is a very well tolerable palliative treatment option for patients with non-resectable advanced cancer of the oesophagus and the gastro-oesophageal junction.

Conflict of interest statement The authors declare that they have no competing interests.

\section{References}

1. Kamangar F, Dores GM, Anderson WF (2006) Patterns of cancer incidence, mortality and prevalence across five continents: defining 
priorities to reduce cancer disparities in different geographical regions of the world. J Clin Oncol 24:2137-2150. doi:10.1200/ JCO.2005.05.2308

2. Cameron AJ, Romero Y (2000) Symptomatic gastro-oesophageal reflux as a risk factor for oesophageal adenocarcinoma. Gut 46:754-755

3. Cunningham D, Starling N, Rao S, Iveson T, Nicolson M, Coxon F, Middleton G, Daniel F, Oates J, Norman AR (2008) Capecitabine and oxaliplatin for advanced esophagogastric cancer. N Engl J Med 358:36-46

4. Al-Batran SE, Hartmann JT, Probst S, Schmalenberg H, Hollerbach S, Hofheinz R, Rethwisch V, Seipelt G, Homann N, Wilhelm G, Schuch G, Stoehlmacher J, Derigs HG, HegewischBecker S, Grossmann J, Pauligk C, Atmaca A, Bokemeyer C, Knuth A, Jaeger E (2008) Phase III trial in metastatic gastroesophageal adenocarcinoma with fluorouracil, leucovorin plus either oxaliplatin or cisplatin: a study of the AIO. J Clin Oncol 26:1435-1442. doi:10.1200/JCO.2007.13.9378

5. Ilson DH, Wadleigh RG, Leichman LP, Kelsen DP (2007) Paclitaxel given by a weekly 1 -h infusion in advanced oesophageal cancer. Ann Oncol 1:898-902. doi:10.1093/annonc/mdm004

6. El-Rayes BF, Shields A, Zalupski M, Heilbrun LK, Jain V, Terry D, Ferris A, Philip PA (2004) A phase II study of carboplatin and paclitaxel in oesophageal cancer. Ann Oncol 15:960-965. doi:10.1093/annonc/mdh230

7. Lorenzen S, Hentrich M, Haberl C, Heinemann V, Schuster T, Seroneit T, Roethling N, Peschel C, Lordick F (2007) Split-dose docetaxel, cisplatin and leucovorin/fluorouracil as first-line therapy in advanced gastric cancer and adenocarcinoma of the gastroesophageal junction: results of a phase II trial. Ann Oncol 18(10):1673-1679

8. Van Cutsem E, Moiseyenko VM, Tjulandin S, Majlis A, Constenla M, Boni C, Rodrigues A, Fodor M, Chao Y, Voznyi E, Risse EL, Ajani JA (2006) Phase III study of docetaxel and cisplatin plus fluorouracil compared with cisplatin and fluorouracil as first-line therapy for advanced gastric cancer: a report of the V325 Study Group. J Clin Oncol 24(31):4991-4997

9. Fujie Y, Yamamoto H, Ngan CY, Takagi A, Hayashi T, Suzuki R, Ezumi K, Takemasa I, Ikeda M, Sekimoto M, Matsuura N, Monden M (2005) Oxaliplatin, a potent inhibitor of survivin, enhances paclitaxel-induced apoptosis and mitotic catastrophe in colon cancer cells. Jpn J Clin Oncol 35(8):453-463

10. Gu J, Yamamoto H, Lu X, Ngan CY, Tsujino T, Konishi K, Takemasa I, Ikeda M, Nagata H, Hashimoto S, Matsuzaki T, Sekimoto M, Takagi A, Monden M (2006) Low-dose oxaliplatin enhances the antitumor efficacy of paclitaxel in human gastric cancer cell lines. Digestion 74(1):19-27

11. Petrasch S, Welt A, Reinacher A, Graeven U, Konig M, Schmiegel W (1998) Chemotherapy with cisplatin and paclitaxel in patients with locally advanced, recurrent or metastatic oesophageal cancer. Br J Cancer 78(4):511-514

12. Therasse P, Arbuck SG, Eisenhauer EA, Wanders J, Kaplan RS, Rubinstein L, Verweij J, Van Glabbeke M, van Oosterom AT,
Christian MC, Gwyther SG (2000) New guidelines to evaluate the response to treatment in solid tumours: European Organization for Research and Treatment of Cancer, National Cancer Institute of the United States, National Cancer Institute of Canada. J Natl Cancer Inst 92(3):205-216

13. Wassermann E, Cuvier C, Lokiec, Goldwasser F, Kalla S, Méry-Mignard D, Ouldkaci M, Besmaine A, Dupont-André G, Mahjoubi M, Marty M, Misset JL, Cvitkovic E (1999) Combination of oxaliplatin plus irinotecan in patients with gastrointestinal tumours: results of two independent phase I studies with pharmacokinetics. J Clin Oncol 17(6):1751-1759

14. André T, Bensmaine MA, Louvet C, François E, Lucas V, Desseigne F, Beerblock K, Bouché O, Carola E, Merrouche Y, Morvan F, Dupont-André G, de Gramont A (1999) Multicenter phase II study of bimonthly high-dose leucovorin, fluorouracil infusion, and oxaliplatin for metastatic colorectal cancer resistant to the same leucovorin and fluorouracil regimen. J Clin Oncol 17(11):3560-3568

15. Richards D, McCollum D, Wilfong L, Sborov M, Boehm KA, Zhan F, Asmar L (2008) Phase II trial of docetaxel and oxaliplatin in patients with advanced gastric cancer and/or adenocarcinoma of the gastroesophageal junction. Ann Oncol 19(1):104-108

16. Polee MB, Sparreboom A, Eskens FA, Hoekstra R, van de Schaaf J, Verweij J, Stoter G, van der Gaast A (2004) A phase I and pharmacokinetic study of weekly paclitaxel and carboplatin in patients with metastatic esophageal cancer. Clin Cancer Res 10(6):19281934

17. Polee MB, Tilanus HW, Eskens FA, Hoekstra R, Van der Burg ME, Siersema PD, Stoter G, Van der Gaast A (2003) Phase II study of neo-adjuvant chemotherapy with paclitaxel and cisplatin given every 2 weeks for patients with a resectable squamous cell carcinoma of the esophagus. Ann Oncol 14(8):1253-1257

18. Winegarden JD, Mauer AM, Otterson GA, Rudin CM, VillalonaCalero MA, Lanzotti VJ, Szeto L, Kasza K, Hoffman PC, Vokes EE (2004) A phase II study of oxaliplatin and paclitaxel in patients with advanced non-small-cell lung cancer. Ann Oncol 15(6):915920

19. Viens P, Petit T, Yovine A, Bougnoux P, Deplanque G, Cottu PH, Delva R, Lotz JP, Belle SV, Extra JM, Cvitkovic E (2006) A phase II study of a paclitaxel and oxaliplatin combination in platinumsensitive recurrent advanced ovarian cancer patients. Ann Oncol 17(3):429-436

20. Lin RB, Fan NF, Guo ZQ, Wang XJ, Liu J, Chen L (2008) A phase II study of 5-fluorouracil/leucovorin in combination with paclitaxel and oxaliplatin as first-line treatment for patients with advanced gastric cancer. J Chemother 20(6):744-748

21. Tanaka R, Ariyama H, Qin B, Takii Y, Baba E, Mitsugi K, Harada M, Nakano S (2005) In vitro schedule-dependent interaction between paclitaxel and oxaliplatin in human cancer cell lines. Cancer Chemother Pharmacol 55(6):595-601

22. Bekaii-Saab TS, Lui J, Chan KK, Balcerzak SP, Ivy P, Grever MR, Kraut EH (2008) A phase I and pharmacokinetic study of weekly oxaliplatin followed by paclitaxel. Clin Cancer Res 14(11):3434-3440 